\title{
T1a Stage Finding
}

National Cancer Institute

\section{Source}

National Cancer Institute. T1a Stage Finding. NCI Thesaurus. Code C48721.

A general term that refers to a TNM finding of a primary tumor limited to the site of growth. The definition of T1a TNM finding depends on the specific type of cancer that it refers to; for example, for breast cancer it refers to a primary tumor that is more than $0.1 \mathrm{~cm}$, but not more than $0.5 \mathrm{~cm}$ in greatest dimension; for kidney cancer it refers to a primary tumor that is $4 \mathrm{~cm}$ or less in greatest dimension; and for thyroid cancer it refers to a primary tumor that is $1 \mathrm{~cm}$ or less in greatest dimension. 